\title{
VERSLO BENDRADARBIAVIMAS KLAIPEDOS REGIONO IR LATVIJOS PASIENYJE
}

\author{
Ligita Šmanskiené ${ }^{1}$, Darius Burgis², Diana Līduma ${ }^{3}$, Māra Zeltiña ${ }^{4}$ \\ Klaipėdos universitetas (Lietuva), Liepojos universitetas (Latvija)
}

\begin{abstract}
ANOTACIJA
Straipsnyje nagrinejjamas organizacijų bendradarbiavimas pasienio regionuose, pristatomi Klaipedos regiono organizacijų apklausos dèl bendradarbiavimo su Latvijos organizacijomis rezultatai. Nustatyta, kad bendradarbiaujama nepakankamai, tačiau yra nemažai organizacijų, kurios tokiu bendradarbiavimu suinteresuotos. Siekiant išsiaiškinti, kas trukdo bendradarbiavimą plètoti, nustatyta, kad užsienio kalba tokia kliūtimi negali būti laikoma, nes jos nemokejjimas sukelia problemų tik mažai daliai regiono organizacijų. Kaip didžiausią kliūti galima ịvardyti informacijos apie galimybes plètoti verslą ir bendradarbiauti su Latvijos organizacijomis trūkumą. Siekiant šias kliūtis pašalinti, siūloma daugiau dèmesio skirti informacijos apie bendradarbiavimo galimybes regione sklaidai. PAGRINDINIAI ŽODŽIAI: Klaipédos regionas, Latvija, bendradarbiavimas, pasienis.
\end{abstract}

JEL KLASIFIKACIJA: R, F230.

Ivadas

Pasaulinės ekonomikos globalizacija daugelyje šalių skatina decentralizacijos ir dereguliacijos procesus, dèl kurių vis didesnį vaidmenị vaidina pagal individualų modelį besivystantys regionai (Šimanskienė, Vaitekūnas, Bučinskas, 2006). Tačiau regionų plètros kontekste dažnai užmirštamas ekonominis potencialas, kylantis iš bendradarbiavimo tarp ìvairių verslo šakų organizacijų. ES šalių narių ir kitų Europos valstybiu tarpregioninis bendradarbiavimas sukuria prielaidas šių regionų ekonomikos ir rinkos plètrai, politiniam stabilumui bei saugumo politikai įtvirtinti, padeda išvengti neigiamų regionų savitarpio konkurencijos padarinių. Ypač aktualus tampa pasienio regionų bendradarbiavimas (Česnavičius, Stanaitis, 2008, Kosiedowski, Stanaitis, 2009). Svarbi užduotis šiuo atveju - sukurti institucinius mechanizmus tarpregioniniam organizacijų bendradarbiavimui skatinti.

1 Ligita Šimanskienè - socialinių mokslų daktarè, profesorè. Klaipėdos universiteto Socialinių mokslų fakulteto Vadybos katedra. Mokslinès kryptys: organizacinè kultūra, konfliktai organizacijose, komandinis darbas, regionų plètra.

El. paštas: ligita_simanskiene@yahoo.com

Tel.: +370 46398666

2 Darius Burgis - asistentas. Klaipėdos universiteto Socialinių mokslų fakulteto Vadybos katedra. Doktorantas. Vytauto Didžiojo universiteto Ekonomikos ir vadybos fakulteto Vadybos katedra. Mokslinès kryptys: kriziniu situacijų valdymas, informacinių technologijų taikymas valdyme.

El.paštas: darius@itinovacijos.lt

Tel.: +370 46398666

3 Diana Līduma - lektorè. Liepojos universiteto Gamtos ir socialinių mokslų fakultetas. Ekonomikos krypties magistrè. Mokslinės kryptys: verslo ekonomika, logistikos valdymas, regionų plètra.

El. paštas: diana_liduma@inbox.lv

Tel.: +371292 65976

4 Māra Zeltiņa - asistentė. Liepojos universiteto Gamtos ir socialinių mokslų fakultetas. Daktarè (biologijos mokslai). Mokslinès kryptys: aplinkosaugos vadyba, darni plètra, regionų plètra.

El. paštas: mara.zeltina@liepu.lv

Tel.: +37129425050 
Šis straipsnis paremtas tyrimo, kuris atliktas rengiant projektą „Regionų verslo plètros skatinimo metodologinių pagrindų kūrimas“ (LT-LV [LV-LT/1.1/LLIII-152/2010]), duomenimis. Juo siekiama pagerinti verslo aplinką, skatinti verslumą Lietuvos ir Latvijos pasienio regionuose (Klaipėdos ir Kuržemès regionai). Pagrindiné problema, su kuria susiduria Lietuvos ir Latvijos pasienio regionas, - žemas konkurencingumas, o vienas iš būdų ji padidinti - aktyvinti pasienio regionų organizacijų bendradarbiavimą.

Šio straipsnio objektas: Klaipedos regiono ir Latvijos organizacijų bendradarbiavimas.

Tikslas: ištirti Klaipėdos regiono organizacijų bendradarbiavimą su Latvijos organizacijomis.

Uždaviniai:

1. Ištirti teorines organizacijų bendradarbiavimo pasienio regionuose prielaidas.

2. Ivertinti Klaipėdos regiono ir Latvijos organizacijų bendradarbiavimo lygi.

3. Nustatyti, kas trukdo bendradarbiauti.

4. Nustatyti, kas gali paskatinti aktyviau bendradarbiauti.

Metodai: mokslinès literatūros analizè ir apibendrinimas, tyrimas atliktas taikant anketinès apklausos metoda.

\section{Teorinès tyrimo prielaidos}

Siena intuityviai suvokiama kaip riba, skirianti dvi ar daugiau skirtingais požymiais pasižyminčių teritorijų. Anot T. Komornicki, ši riba gali būti teisinè, administracinè, infrastruktūros, ekonominè ar psichologinė (remiantis Michalski, 2008). Dažnai viena riba skatina kitų atsiradimą bet gali paskatinti ir bendrą veiklą, kuri nulemtų viso pasienio regiono vystymąsi ir jame veikiančių organizacijų konkurencingumo didèjimą (Dolzblasz, Lesniak, 2005). Siekiant plètoti pasienio regionų organizacijų bendradarbiavimą būtinos tam tikros sąlygos. Informacinès komunikacijos technologijos (IKT) gali būti pagrindinè sąlyga, būtina, norint koordinuoti skirtingose geografinèse vietovėse esančiu individu ir organizacijų veiklą, taigi jas galima laikyti tarptautinio ir regioninio bendradarbiavimo pagrindu (Czochanski, 2006; Contractor, 2007). IKT ne tik palengvina apsikeitimo informacija tarp skirtingose geografinèse vietovėse esančių organizacijų procesą, bet ir leidžia sukurti modernias koordinavimo sistemas, kurios užtikrina tinklinių organizacijų veikimą (Burgis, Ribačonka, 2011).

Kita svarbi sąlyga, nulèmusi tarptautinį bendradarbiavimą verslo srityje, - anglų kalbos tapimas visuotinai priimta bendravimo priemone. F. J. Contractor (2007) nurodè, kad 85 procentai tarptautinių asociacijų vartojo anglų kalbą kaip pagrindinę bendravimo priemonę, o 33 procentai bendrauja tik anglų kalba. Kalbant apie posovietinio bloko valstybes ir regionus reikètų paminèti, kad ilgą laiką pagrindinès tarptautinio bendravimo priemonès vaidmeni čia atliko rusų kalba, dažnai jos svarba skatinant bendradarbiavimą jaučiama ir dabar.

Organizacijų bendradarbiavimas tampa esmine naujo verslo organizavimo modelio globalioje ekonomikoje dalimi. Šiandien didžiausi ekonominiai dariniai yra ne multinacionalinès korporacijos, bet globalūs verslo tinklai, kuriuos sudaro vienu metu ir konkuruojančios, ir bendradarbiaujančios organizacijos (Castells, 2005). Pastebėtina, kad intensyvejo tiek vertikalus (bendradarbiaujančios organizacijos užima skirtingas tiekimo grandinės pakopas), tiek horizontalus (susivienijimus vienija partneriai, kurie sutelkia jègas ir turimus išteklius toms pačioms verslo funkcijoms igyvendinti) bendradarbiavimas (Contractor, 2007). Tuo tarpu A. Saxenian (1994) teigia, kad skatinant darnią klasterių plètrą, regioniniai horizontalūs lankstūs tarporganizaciniai tinklai, sujungiantys mažas ir vidutines organizacijas, yra daug svarbesni nei vertikalia integracija besiremiantis bendradarbiavimas. T. Arita ir kt. (2006), tyręs Japonijos organizacijas, nustatè, kad bendradarbiauti su kitomis institucijomis linkusios organizacijos, tikètina, augs sparčiau nei bendradarbiauti nelinkusios. Ypač svarbus horizontalus bendradarbiavimas tarp skirtingų verslo šakų organizacijų ir universitetų. Svarbus vaidmuo šiame procese tenka valstybinėms institucijoms, pavyzdžiui, P. L. Chee (1984), tyrinèjęs ASEAN organizacijų bendradarbiavima, siūlo regioniniame lygmenyje valstybei koordinuoti savo veiksmus skatinant verslą. Kiekvienoje šalyje galètų būti paskirta institucija ar agentūra, kurios pagrindinis uždavinys būtų koordinuoti regioninį bendradarbiaujančių organizacijų tinklą, kuris skatintų keistis informacija ir puoselèti naujus bendradarbiavimo ryšius. 


\section{Klaipedos regiono ir Latvijos organizaciju bendradarbiavimo tyrimas}

Anketinei apklausai atlikti sudarytas klausimynas, tyrimo imtis apskaičiuota pagal Panioto formulę (Kardelis, 2005). Kadangi tyrimas buvo atliekamas Klaipėdos, Kauno ir Kuržemės regionuose, o apklausiami šiuose regionuose veikiančių organizacijų vadovai, tiriamają populiaciją sudare trijuose regionuose veikiančios organizacijos, konkrečiai: $10254+16168+16846=43268$. Irašę duomenis ị Panioto formulę gauname tyrimo imtị: $n=1 /\left(0,05^{2}+1 / 43268\right)=396,336$, taigi norint gauti rezultatus, kurių patikimumas būtų $95 \%$, reikia apklausti 396 organizacijų vadovus trijuose regionuose. Siekiant patikimesnių rezultatų nuspręsta apklausti 450 organizacijų. Padalijus gautą skaičių iš trijų, gautas organizacijų, kurias reikia apklausti kiekviename regione, skaičius - 150. Kad būtų tiksliai atskleista bendra regiono situacija, nuspręsta atsižvelgti ị organizacijų ekonominès veiklos šaką, tai yra tam tikros ekonominès veiklos šakos organizacijų, kurios turi būti apklaustos Klaipėdos regione, skaičių lemia šios šakos santykis tarp visų organizacijų, veikiančių Klaipėdos regione (žr. 1 lentelę).

1 lentelè. Organizacijų, kurias būtina apklausti Klaipėdos regione, skaičius pagal ekonominės veiklos šaką

\begin{tabular}{|l|r|r|r|}
\hline \multicolumn{1}{|c|}{ Ekonominès veiklos šaka } & Organizacijų regione skaičius & \multicolumn{1}{c|}{$\begin{array}{c}\text { Būtinu apklausti } \\
\text { organizacijų skaičius }\end{array}$} \\
\hline Žemės ūkis, miškininkystè ir žuvininkystė & 187 & 1,82 & $\mathbf{3}$ \\
\hline Pramonė & 862 & 8,4 & $\mathbf{1 3}$ \\
\hline Aplinka ir energetika & 69 & 0,67 & $\mathbf{1}$ \\
\hline Statyba & 996 & 9,71 & $\mathbf{1 5}$ \\
\hline Prekyba & 2404 & 23,44 & $\mathbf{3 5}$ \\
\hline Paslaugos & 3356 & 32,72 & $\mathbf{4 9}$ \\
\hline Finansine ir draudimo veikla & 64 & 0,62 & $\mathbf{1}$ \\
\hline Viešasis administravimas & 46 & 0,44 & $\mathbf{1}$ \\
\hline Švietimas & 357 & 3,48 & $\mathbf{5}$ \\
\hline Sveikata ir socialinis darbas & 288 & 2,8 & $\mathbf{4}$ \\
\hline Kita & 1625 & 15,84 & $\mathbf{1 0}$ \\
\hline IŠ VISO & $\mathbf{1 0 2 5 4}$ & $\mathbf{1 0 0}$ & $\mathbf{1 5 0}$ \\
\hline
\end{tabular}

Šaltinis: Statistikos departamentas prie Lietuvos Respublikos Vyriausybès, 2010.

Apklausoje dalyvavo 159 organizacijos, kurios turejjo nurodyti savo ekonominès veiklos grupę. Klaipédos regione dauguma organizacijų užsiima paslaugų teikimu ir prekyba (atitinkamai 33,5 \% ir 23,5 \%), šios dvi grupès kartu sudaro $56 \%$ visų regione apklaustų organizacijų, taigi tyrimo požiūriu ši organizacijų grupè yra pati svarbiausia. Kitos veiklos šakos, būdingos Klaipėdos regionui, - pramonès ir statybos sektoriai, kuriuose apklausta atitinkamai 7,0 \% ir 7,5\% veikiančių organizacijų. 12,0\% apklaustų organizacijų nurode „kitą“ veiklos šaką, tačiau daugeliu atvejų šias organizacijas būtu galima vertinti kaip kitas paslaugas teikiančias organizacijas. Apklaustų organizaciju skaičius ir pasiskirstymas pagal veiklos šaką atitinka tyrimo metodologijoje apskaičiuotą imti (apklaustos 159 organizacijos, imtis - 150) bei pasiskirstymo pagal ekonominès veiklos šakas Klaipėdos regione santyki.

Daugelis tyrime dalyvavusių organizacijų yra smulkios, jose dirba mažiau nei 10 darbuotojų (mikroịmonés), tai sudaro $61,1 \%$ visų apklaustų organizacijų. $18,9 \%$ apklaustų organizacijų priskirtinos mažu immoniu kategorijai, jose dirba nuo 10 iki 50 darbuotojų. Net 80,3\% tyrime dalyvavusių organizacijų turèjo mažiau kaip 50 darbuotojų, tai atitinka bendrą regiono tendenciją, kad didžiają dalị organizacijų sudaro smulkiojo ir vidutinio verslo organizacijos. Vis dèlto apklausoje dalyvavo ir 10,2 \% dideliu organizacijų, kuriose dirba daugiau kaip 250 darbuotoju. Panašią tendenciją matysime ir vertindami tyrime dalyvavusias organizacijas pagal jų metinę apyvartą. 77,4 \% tyrime dalyvavusių organizacijų metinė apyvarta nesiekia 7 milijonų litų, 89,2\% organizacijų metinè apyvarta neviršija 24 milijonų litų. Apie 6,9\% atsakiusiujų nurodè, kad jų metiné apyvarta yra tarp 24 ir 138 mln. Lt. Tik 3,8 \% atsakiusiujų nurodè, kad metinė apyvarta didesnè kaip138 mln. Lt. 
Atsižvelgiant $\mathfrak{i}$ tai, kiek metų veikia tyrime dalyvavusios organizacijos, jos pasiskirste gana tolygiai: didžioji dalis organizacijų veikia nuo vienerių iki dešimties metų, 34 \% organizaciju jau veikia ilgiau kaip vienuolika metur.

Apibendrinant galima teigti, kad tyrime dalyvavusių organizacijų pasiskirstymas pagal ekonominès veiklos šaką, darbuotojų skaičių ir metinę apyvartą atitinka Klaipėdos regiono organizacijų pasiskirstymą pagal šiuos parametrus, be to, apklaustos įvairios gyvavimo trukmès organizacijos, o tai leidžia teigti, kad gauti duomenys tinkamai atskleis bendrą Klaipėdos regiono situaciją regioninio bendradarbiavimo aspektu.

Nors Lietuva ir Latvija yra mažos ir panašiai ekonominiu požiūriu išsivysčiusios kaimynès, dažniausiai jos ieško partnerių didesnèse rinkose, kaip Europos Sajungos šalys, Rusijos Federacija ar panašiai. Todèl tyrimo metu gauti rezultatai, kad tik 18,2\% apklaustų organizacijų turi partnerių Latvijoje, nenustebino (žr. 2 lentelę).

2 lentele. Klaipèdos regiono ir Latvijos organizacijų bendradarbiavimas

\begin{tabular}{|l|r|r|}
\hline Ar turite verslo partnerių Latvijoje? & Organizacijų skaičius & Procentas \\
\hline Neatsake & 3 & $1,9 \%$ \\
\hline Taip & 29 & $18,2 \%$ \\
\hline $\mathrm{Ne}$ & 127 & $79,9 \%$ \\
\hline Iš viso & 159 & $100,0 \%$ \\
\hline
\end{tabular}

Kaip matome iš pateiktų duomenu, 29 verslo organizacijos turi verslo partnerių Latvijoje, tačiau pažiūrèję, su kokiomis veiklos šakomis bendradarbiaujama (3 lentelè), pamatysime, kad šios įmonès užmezgusios 42 bendradarbiavimo ryšius su i̇vairių verslo šakų organizacijomis Latvijoje. Tai rodo, kad dalis verslo organizacijų bendradarbiauja su keliomis skirtingose šakose veikiančiomis organizacijomis. Manome, kad tokios geros bendradarbiavimo patirties reikètu paskleisti ir kitoms verslo organizacijoms, kad jos matytu tokio bendradarbiavimo naudą.

3 lentele. Klaipėdos regiono organizacijų partneriai Latvijoje pagal ekonominės veiklos šakas

\begin{tabular}{|l|r|r|}
\hline \multirow{2}{*}{ Ekonominės veiklos šakos } & \multicolumn{2}{|c|}{ Atsakymai } \\
\cline { 2 - 3 } & Partnerių skaičius & Procentais \\
\hline Žemės ūkis, miškininkystè ir žuvininkystė & 1 & $2,4 \%$ \\
\hline Pramonė & 5 & $11,9 \%$ \\
\hline Aplinka ir energetika & 1 & $2,4 \%$ \\
\hline Statyba & 3 & $7,1 \%$ \\
\hline Prekyba & 12 & $28,6 \%$ \\
\hline Paslaugos & 8 & $19,0 \%$ \\
\hline Finansai ir draudimas & 1 & $2,4 \%$ \\
\hline Viešasis administravimas & 2 & $4,8 \%$ \\
\hline Švietimas & 7 & $16,7 \%$ \\
\hline Sveikata ir socialinis darbas & 2 & $4,8 \%$ \\
\hline Iš viso & $\mathbf{4 2}$ & $\mathbf{1 0 0 , 0} \%$ \\
\hline
\end{tabular}

Daugiausiai partnerių turima Latvijos prekybos (28,6\%), paslaugų (19,0 \%) ir švietimo (16,7\%) sektoriuose. Akivaizdu, kad būtent šios sritys yra lanksčiausios, labiausiai ieškančios naujų rinkų, galimybių. Partnerių Latvijoje turinčių Klaipèdos regiono organizacijų bendradarbiavimo pobūdis pavaizduotas 4 lentelèje. 
4 lentelè. Klaipėdos regiono ir Latvijos organizacijų bendradarbiavimo pobūdis

\begin{tabular}{|l|r|r|}
\hline \multirow{2}{*}{ Bendradarbiavimo pobūdis } & \multicolumn{2}{|c|}{ Atsakymai } \\
\cline { 2 - 3 } & Organizacijų skaičius & \multicolumn{1}{c|}{ Procentai } \\
\hline Žaliavų pirkimas & 5 & $11,4 \%$ \\
\hline Prekių pirkimas & 8 & $18,2 \%$ \\
\hline Paslaugų pirkimas & 15 & $34,1 \%$ \\
\hline Gamyba & 3 & $6,8 \%$ \\
\hline Bendri prekybos kanalai & 8 & $18,2 \%$ \\
\hline Kita & 5 & $11,4 \%$ \\
\hline Iš viso & $\mathbf{4 4}$ & $\mathbf{1 0 0 , 0} \%$ \\
\hline
\end{tabular}

Remdamiesi gautais duomenimis matome, kad bendradarbiavimo pobūdis atitinka esamų partnerių šakas: paslaugų pirkimas (34,1\%), prekių pirkimas (18,2\%) ir bendri prekybos kanalai (18,2\%). Mažiausiai bendradarbiauja gamybos imonès. Penkios organizacijos, pasirinkusios variantą „kita“, nurodè atitinkamai: „transporto paslaugos" (ši atsakymą reikètų dèti prie paslaugu pirkimo, taigi ši bendradarbiavimo rūšis padidètu iki 36,36 \%); ,akademinis bendradarbiavimas“; „inovacijos“; „,bendra tiriamoji veikla“. Akademini bendradarbiavimą ir bendrą tiriamają veiklą, kaip bendradarbiavimo pobūdị, nurodè švietimo srityje veikiančios organizacijos, akivaizdu, kad tai labai svarbi bendradarbiavimo kryptis. Bendradarbiavimą inovacijų srityje nurodžiusi organizacija yra verslo paramos agentūra, tai puikus skirtingu šaliu organizacijų bendradarbiavimo pavyzdys.

5 lentelè. Klaipėdos regiono organizacijas dominantys partneriai Latvijoje pagal ekonominès veiklos šakas

\begin{tabular}{|l|r|r|}
\hline \multirow{2}{*}{ Domintų šių šakų partneriai } & \multicolumn{2}{|c|}{ Atsakymai } \\
\cline { 2 - 3 } & \multicolumn{1}{|c|}{ Skaičius } & \multicolumn{1}{c|}{ Procentai } \\
\hline Žemės ūkis, miškininkystė ir žuvininkystė & 5 & $4,5 \%$ \\
\hline Pramonė & 12 & $10,9 \%$ \\
\hline Aplinka ir energetika & 8 & $7,3 \%$ \\
\hline Statyba & 12 & $10,9 \%$ \\
\hline Prekyba & 21 & $19,1 \%$ \\
\hline Paslaugos & 29 & $26,4 \%$ \\
\hline Finansai ir draudimas & 6 & $5,5 \%$ \\
\hline Viešasis administravimas & 3 & $2,7 \%$ \\
\hline Švietimas & 8 & $7,3 \%$ \\
\hline Sveikata ir socialinis darbas & 1 & $0,9 \%$ \\
\hline Kita & 5 & $4,5 \%$ \\
\hline Iš viso & $\mathbf{1 1 0}$ & $\mathbf{1 0 0 , 0} \%$ \\
\hline
\end{tabular}

Kaip matome iš 5 lentelèje pateiktų duomenų, Lietuvos verslininkai norètų daugiau bendradarbiauti su ¡vaairių verslo šakų partneriais. Palyginę šiuos duomenis su ankstesniais duomenimis (kuriose šakose organizacijos turi partneriu), pamatytumėm, kad siekiama turèti daugiau partnerių nei turima dabar visose šakose. Tai rodo, kad galima ir reikia toliau plètoti kaimyninių šalių bendradarbiavimą. Būtina tų verslo šakų verslininkams padèti daugiau sužinoti apie galimus bendradarbiavimo būdus įvairiose verslo šakose. Lietuvos verslininkai nori bendradarbiauti žemės ūkio srityje: nustatytas 1 bendradarbiavimo ryšys, norima penkių; pramonèje - nuo 5 bendradarbiavimo ryšiu iki 12 norimų; aplinkos ir energetikos srityje - nuo 1 bendradarbiavimo ryšio iki 8 norimu;; statybos versle - nuo 3 bendradarbiavimo ryšių iki 12 norimų; prekyboje - nuo 12 bendradarbiavimo ryšių iki 21 norimų; paslaugų sektoriuje - nuo 8 bendradarbiavimo ryšių iki 29 norimų; finansų ir draudimo šakose - nuo 1 bendradarbiavimo ryšio iki 6 norimų; viešojo administravimo - nuo 2 bendradarbiavimo ryšių iki 3 norimu; švietime - nuo 7 bendradarbiavimo ryšių iki 8 norimų.

Bendras Klaipèdos regiono organizacijų domèjimasis partneriais Latvijoje pavaizduotas 6 lentelèje. 
6 lentele. Partneriais Latvijoje besidominčios Klaipėdos regiono organizacijos

\begin{tabular}{|l|r|r|}
\hline Ar Jus domintų verslo partneriai Latvijoje? & Organizacijų skaičius & Procentas \\
\hline Neatsake & 3 & $1,9 \%$ \\
\hline Taip & 68 & $42,8 \%$ \\
\hline $\mathrm{Ne}$ & 88 & $55,3 \%$ \\
\hline Iš viso & $\mathbf{1 5 9}$ & $\mathbf{1 0 0 , 0} \%$ \\
\hline
\end{tabular}

Kaip matome iš pateiktų duomenų, 42,8 \% Klaipėdos organizacijų norètų bendradarbiauti su Latvijos organizacijomis, tai galima vertinti kaip gana didelę dalị. Teigiamai nuteikia ir tai, kad šiuo metu partnerių Latvijoje turi 18,2 \% visų tyrime dalyvavusių organizacijų, norètų turèti 42,8 \%. Kaip matome, šis skaičius išaugo daugiau negu dvigubai. Jei šios verslo organizacijos pradètų bendradarbiauti su kaimyninès šalies verslininkais, būtų akivaizdi ekonominè nauda tiek Lietuvos, tiek Latvijos ekonomikai. Turint omenyje tokį didelį turinčių ir norinčių turèti partnerių Latvijoje skirtumą, galima daryti prielaidą, kad egzistuoja tam tikri bendradarbiavimą ribojantys veiksniai, vienas jų pavaizduotas 7 lentelejje.

7 lentele. Informacijos apie verslą Latvijoje stoka

\begin{tabular}{|l|r|r|}
\hline $\begin{array}{c}\text { Ar Jums pakanka informacijos apie verslą Latvijoje } \\
\text { (istatymai, mokesčiai, ir kt.)? }\end{array}$ & Organizacijų skaičius & Procentai \\
\hline Neatsake & 7 & $4,4 \%$ \\
\hline Taip & 44 & $27,7 \%$ \\
\hline Ne & 108 & $\mathbf{1 5 9}$ \\
\hline Iš viso & $\mathbf{1 5 9}$ & $\mathbf{1 0 0 , 0} \%$ \\
\hline
\end{tabular}

Didžioji dalis respondentų teigè, kad informacijos jiems nepakanka, prisiminus, kad dalis respondentų nesiekia turèti partnerių Latvijoje, galima būtų teigti, kad menkas susidomėjimas gali būti susijęs su informacijos apie verslo galimybes trūkumu. Manome, kad papildoma informacija skatintų verslininkus pagalvoti apie perspektyvą plėsti verslą / paslaugas kaimyninejje šalyje. Turètų būti daugiau galimybių sužinoti verslo naujienas, kas vyksta Latvijoje, taip būtų sudarytos sąlygos naujiems verslo santykiams. Bendradarbiavimą ivairiose verslo šakose puoselèja 29 organizacijos, o 108 verslo organizacijos teigia, kad joms reikia papildomos informacijos, taigi dar yra galimybių verslo informaciniams centrams ar vietos savivaldybems aktyviau skleisti informaciją.

Bendradarbiavimą regione galètų stabdyti ir užsienio kalbos nemokejjimas. Respondentu atsakymų i ši klausimą pasiskirstymas pavaizduotas 8 lentelèje.

8 lentelè. Užsienio kalbos nemokèjimas, kaip kliūtis plètoti verslą Latvijoje

\begin{tabular}{|l|r|r|}
\hline Ar užsienio kalba yra kliūtis plètoti verslą Latvijoje? & Organizacijų skaičius & \multicolumn{2}{|c|}{ Procentai } \\
\hline Neatsake & 3 & $1,9 \%$ \\
\hline Taip & 44 & $27,7 \%$ \\
\hline Ne & 112 & $70,4 \%$ \\
\hline Iš viso & $\mathbf{1 5 9}$ & $\mathbf{1 0 0 , 0} \%$ \\
\hline
\end{tabular}

$27,7 \%$ respondentų teige, kad tai trukdo plètoti verslą, tačiau didžiosios respondentų dalies teigimu, tai ne kliūtis. Kadangi tiek Lietuva, tiek Latvija yra nedidelès šalys, jų gyventojai priversti mokytis užsienio kalbų. Tradiciškai vyresnioji karta moka rusų kalbą, beje, abiejose šalyse dalis vietos gyventojų (piliečių) yra kitataučiai: rusai, baltarusiai, ukrainiečiai, todèl gali susikalbèti šia kalba. Jaunesnioji karta dažniausiai moka anglų kalbą, tai pasaulyje pripažinta verslo kalba, todèl verslo organizacijos randa galimybių bendrauti. Be abejo, kiekviena šalis turi savitą kultūra, istoriją ir kalba, kaip priemonè jai išreikšti, yra ypač svarbus 
elementas, padedantis sukurti nuoširdumo atmosferą. Jeigu žmonės nemoka kalbėti kurios nors šalies gimtaja kalba, sumažěja galimybių visiškai laisvai išreikšti mintis, poreikius, lūkesčius versle, suvokti tautini identitetą, norint geriau pažinti partnerị. Tačiau plètojant verslą tai dažniausiai nèra esminè problema, nebent tai būtų verslas, nukreiptas tik ị vietinę rinką, tada mokèti vietinę kalbą būtų būtinybẻ. 9 lentelèje matome Klaipėdos organizacijų informacijos dèl verslo galimybių Latvijoje poreikị gimtaja kalba.

9 lentelè. Informacijos dèl verslo galimybių Latvijoje poreikis lietuvių kalba

\begin{tabular}{|l|r|r|}
\hline $\begin{array}{c}\text { Ar Jums reikia informacijos apie verslo galimybes Latvijoje } \\
\text { lietuvių kalba? }\end{array}$ & Organizacijų skaičius & \multicolumn{1}{c|}{ Procentai } \\
\hline Neatsake & 3 & $1,9 \%$ \\
\hline Taip & 82 & $51,6 \%$ \\
\hline $\mathrm{Ne}$ & 74 & $46,5 \%$ \\
\hline Iš viso & $\mathbf{1 5 9}$ & $\mathbf{1 0 0 , 0} \%$ \\
\hline
\end{tabular}

Nors didžioji dalis respondentų teigè, kad kalbos nemokẻjimas nėra kliūtis plètoti verslą, tačiau 51,6 \% vis dèlto norètų turèti informacijos apie verslo galimybes Latvijoje lietuvių kalba. Tai dar kartą patvirtina, kad informacijos trūkumas yra akivaizdus.

Išanalizavus verslo šakas ir darbuotojų skaičiu jose galima konstatuoti, kad didžioji dalis yra mažos ịmonès, kurios turi apie 10 darbuotojų. Tokie rezultatai yra žemės ūkio, miškininkystės ir žuvininkystės verslo, aplinkos ir energetikos, finansų ir draudimo, viešojo administravimo organizacijose. Pramonès, prekybos ir paslaugu verslo organizacijos buvo îvairaus dydžio (ir smulkios, ir vidutinès, ir didelès). Švietimo, socialinio darbo ir sveikatos verslo organizacijos buvo arba mažos, arba jose dirbo daugiau kaip 250 darbuotojų. Ši informacija tyrimui taip pat svarbi, nes reikia žinoti, kaip pateikti informaciją verslo šakų atstovams, kad ją suprastų, o svarbiausia - gautų. Jeigu organizacijos labai didelès, dèl gausaus įvairios informacijos kiekio informacija apie verslo galimybes Latvijoje gali ir nepatekti ten, kur priimami sprendimai dèl galimo bendradarbiavimo.

Rezultatai rodo, kad didžioji dalis apklaustų organizacijų veikia nuo 7 iki 10 metų. Tik viena organizacija dirbo metus. Didžiausias pasiskirstymas prekybos ir paslaugų organizacijose, jos visos dirba daugiau negu metus laiko, kai kurios - daugiau kaip 11 metú. Todèl galime teigti, kad tai patirties turinčios organizacijos, sugebejjusios išlikti per ekonominę krizę. Puiku, kad šios organizacijos ieško bendradarbiavimo galimybiu ne tik savoje, bet ir kaimyninèse šalyse.

Rezultatai rodo, kad organizacijų, kurios turi verslo partnerių Latvijoje, metinė apyvarta yra tiek pat ivairi, kaip ir organizaciju, kurios neturi verslo partnerių Latvijoje. Reikia tik priminti, kad organizacijų, turinčiu verslo partnerių, skaičius gerokai mažesnis, bet ir ten yra organizacijų, kurios viršija $138 \mathrm{mln}$. litu apyvartą. Tiek organizacijose, kurios turi verslo partnerių, tiek organizacijose, kurios jų neturi, darbuotojų skaičius yra vienodas. Todèl negalime teigti, kad tik mažos ar didelès organizacijos linkusios bendradarbiauti, tai labiau priklauso nuo organizacijos igyvendinamos strategijos. İdomu pažymėti, net 82,8 proc. tyrime dalyvavusių organizacijų, turinčių verslo ryšių su kaimynine šalimi, teigia, kad joms reikia informacijos apie verslo galimybes Latvijoje lietuvių kalba. Taigi galime teigti, kad tokiu bendradarbiavimu šios organizacijos patenkintos, tiesiog nori dar daugiau sužinoti ir praplèsti bendradarbiavimo galimybes. Tuo tarpu organizacijos, turinčios verslo partnerių Latvijoje, apskritai dẻl informacijos apie verslo galimybes Latvijoje stokos nesiskundžia ir didelio poreikio tam neturi. Bendros informacijos apie verslo galimybes Latvijoje labiau norètų organizacijos, kurios šiuo metu nebendradarbiauja su kaimyninès šalies verslo organizacijomis.

Organizacijos, kurias domintu verslo partneriai Latvijoje, teigia, kad joms reikia informacijos apie verslo galimybes Latvijoje. İdomu paminèti, kad net tos organizacijos, kurios teigia nesidominčios verslo partneriais Latvijoje, teigia, kad joms trūksta informacijos apie verslo galimybes kaimyninėje šalyje. Reikia pažymèti, kad organizacijas, kurias domina galimybè rasti verslo partnerių Latvijoje, iš tiesų nelabai stabdo latviu kalbos nemokejjimas. Tik 14 galimybe bendradarbiauti su Latvija besidominčių verslo organizacijų nurodè, kad kalbos nemokëjimas yra kliūtis, tuo tarpu net 53 verslo organizacijos tokios kliūties neįžvelgia. 


\section{Išvados}

Organizacijų bendradarbiavimas sudarant horizontalius tinklus yra vienas pagrindinių naujo verslo modelio globaliame pasaulyje bruožų. Organizacijų bendradarbiavimas yra vienas jų plètrą skatinančių veiksnių. Tikètina, kad sparčiau vystantis organizacijoms gerès ir bendra pasienio regionų ekonominè situacija, mažès socialinė ir ekonominè atskirtis. Palankias sąlygas šalių organizacijų bendradarbiavimui sudaro IKT paplitimas ir anglų, kaip universalios, kalbos vartojimas.

$18,2 \%$ tyrime dalyvavusių organizacijų nurodè turinčios verslo partnerių Latvijoje, daugiausia bendradarbiaujama prekybos $(28,6 \%)$, paslaugu $(19,0 \%)$ ir švietimo $(16,7 \%)$ sektoriuose. Tai, kad labiausiai bendradarbiauja prekybos ir paslaugų organizacijos, lemia ir bendradarbiavimo pobūdị: paslaugu pirkimas $(34,1 \%)$, prekiu pirkimas $(18,2 \%)$ ir bendri prekybos kanalai $(18,2 \%)$. Kaip papildomos bendradarbiavimo sritys nurodyti akademinis bendradarbiavimas, bendradarbiavimas inovacijų srityje ir bendra tiriamoji veikla. Atliekant tyrimą paaiškejjo, kad nors šiuo metu Klaipèdos regiono ir Latvijos organizacijų bendradarbiavimas nèra intensyvus, egzistuoja didelis tokio bendradarbiavimo poreikis: net $42,8 \%$ tyrime dalyvavusių organizacijų norètų bendradarbiauti su Latvijos organizacijomis, tai yra beveik du kartus daugiau nei bendradarbiauja šiuo metu, ši tendencija pastebima visose ekonominès veiklos šakose.

27,7 \% respondentų teigia, kad užsienio kalbos nemokejjimas trukdo bendradarbiauti su Latvijos organizacijomis. Kadangi tiek Lietuva, tiek Latvija yra nedidelès šalys, jų gyventojai priversti mokytis užsienio kalbos. Tradiciškai vyresnioji karta moka rusų kalbą, jaunesnioji dažniausiai moka anglų kalbą, kuri pasaulyje pripažinta kaip verslo kalba, todèl verslo organizacijos paprastai suranda galimybių bendrauti. Didesnè kliūtis Klaipėdos regiono ir Latvijos organizacijų bendradarbiavimui yra informacijos apie verslo vykdymo sąlygas Latvijoje trūkumas. Net 67,9 \% tyrime dalyvavusių organizacijų nurodè, kad tokios informacijos jiems trūksta, taip pat išsakytas pageidavimas tokios informacijos gauti lietuvių kalba.

Siekiant paspartinti Klaipèdos regiono ir Latvijos organizacijų bendradarbiavimą reikètų daugiau informacijos apie verslo plètojimo galimybes Latvijoje, jei i̇manoma tokia informacija turètų būti prieinama lietuvių kalba, reikètų koordinuojančio didesnio abiejų valstybių institucijų vaidmens, kurti horizontalius bendradarbiavimo tarp valstybès, švietimo ir verslo organizacijų tinklus, tinklinių organizacijų veikloje galètų dalyvauti ir partneriai iš Latvijos.

\section{Literatūra}

Arita, T., Fujita, M., Kameyama, Y. (2006). Efects of Regional Cooperation Among Small and Medium-sized firms onf their Growth in Japanese Industrial Clusters. RURDS, Vol. 18, No. 3 p. 209-228.

Castells, M. (2005). Tinklaveikos visuomenés raida. Kaunas: Poligrafija ir informatika.

Chee, P. L. (1984). Small Enterprises in ASEAN: Need for regional co-operation. ASEAN Economic Bulletin, p. 89-114.

Contractor, F. J. (2007). Interorganizationai Cooperation and Our Manifest Destiny: an evolutionary perspective. Futures Research Quarterly, Vol. 23, Issue 2, p. 5-29.

Czochanski, J. T. (2006). IT technologies and systems as factors contributing to developing integration and co-operation in Baltic Sea Region. Baltic Europe from idea to reality, p. 136-147.

Česnavičius, D., Stanaitis, S. (2008). Prigraničnoje ekonomičeskoje sotrudnečestvo v kontekste Evropeiskoj integracii (Primer Litvy). Problemy V spolpracy Gospodarczej V regionie Baltyckim V kontekšcie integracji Europejskiej, s. 105-114.

Dolzblasz, S., Lesniak, M. (2005). Conditions of competitiveness in the borderlads in the context of European integration. Problems of regional and local development in Polish, Russian and Lithuanian parts of South Baltic arc., p. $29-42$.

Kardelis, K. (2007). Moksliniu tyrimu metodologija ir metodai. Kaunas: Technologija.

Korneyevets, V. (2004). Kaliningrad oblast as a region of co-operation in the Baltic region. In: T. Palmowski (ed.). The framework of regional development in cross-border areas of north-eastern Poland and the Kaliningrad oblast. Gdynia-Pelpin, s. 33-43.

Lepik, K. (2009). Euroregions as mechanisms for strengthening cross-border cooperateon in the Baltic Sea region. TRAMES: A Journal of the Humanities \& Social Sciences, Vol. 13 Issue 3, p. 265-284.

Michalski, T. (2008). Global, continental and regional context of the functioning of new European borders. Tiltai, Nr. 1, p. 7-14. 
Saxenian, A. (1994). Regional Advantage: Culture and Competition in Silicon Valley and Route 128. Cambridge, MA: Harvard University Press.

Statistikos departamentas prie Lietuvos Respublikos Vyriausybès. (2010). Ūkio subjektai. Pagrindiniai duomenys.

Šimanskienè, L. (2007). Research of Regional and Territorial Development problems including the initiatives of Cross Border Cooperation in fields of Science and Technologies. Establishment of the Bipolar Area of Science and Research Klaipeda-Kaliningrad. Scientific analytical reports. Klaipeda: Klaipeda University, p. 44-99.

Šimanskienè, L., Vaitekūnas, S., Bučinskas, A. (2006). Regional problems of Lithuania in the context of the EU. In: W. Karaszewkiego, S. Kunikowskiego (eds.). Polityka Rozwoju Europy Srodkowo-Wschodniej. Aspekty makroekonomoczne i regionalne. Wloclawek: Lega Oficina Wydawnicza, p. 225-242.

\title{
BUSINESS COOPERATION IN THE CROSS-BORDER OF KLAIPEDA REGION AND LATVIA
}

\author{
Ligita Šimanskiené, Darius Burgis, Diana Līduma, Māra Zeltiña \\ Klaipėda University (Lithuania), Liepaja University (Latvia)
}

\section{Summary}

In this article we analyse the cooperation of business organisations of Klaipeda region with Latvian organizations. One of the main problems of this region, located in the cross-border with Latvia, is low competiveness of its organisations and high levels of unemployment. One of ways of coping with this problem is promoting the cooperation between organisations in the region among themselves and also with organisations in neighbouring Latvia. In this article we present the results of the research done in 2011 among top managers of organizations in Klaipeda region, the aim of the research and also this article is to examine the state of cooperation between organizations of Klaipeda region and Latvia. The tasks of the article are: 1) to analyse the theoretical premises for cooperation in cross-border regions; 2) determine the level of cooperation of organisations from Klaipeda region and Latvia; 3) determine the obstacles for cooperation; 4) establish the measures that could stimulate more active cooperation of organisations of Klaipeda region and Latvian organizations. To achieve these goals we used the analysis of scientific literature and survey research.

A total of 159 organisations took part in the survey, to better reflect the real situation in the region, we decided to survey organizations according to their branch of economic activity, that is the number of organizations surveyed in each branch of economic activity was determined by the proportion of organizations in specific branch of economic activity among total number of organizations in the region. Most organizations that participated in the survey are engaged in services and trade, $33.5 \%$ and $23.5 \%$ respectively. Most of the organizations that participated in the research have fewer than 10 employees (micro enterprises), they constitute of $61.1 \%$ of all questioned organizations, $18.9 \%$ are small enterprises employing between 10 and 50 employees. Even $80.3 \%$ of organizations participated in the research had fewer than 50 employees. $77.4 \%$ of surveyed organizations had annual turnover below 7 million LTL. The distribution of enterprises by number of employees and by the annual turnover of the organizations that participated in the survey correspond with the actual situation in Klaipeda region, where most of the organizations are small and medium enterprises, mostly engaged in services and trade branches of economic activity.

After analysing the scientific literature and the data from the survey research we came to the following conclusions:

Cooperation by forming horizontal networks is one of the main aspects of doing successful business in a globalised world. Cooperation between organizations is one of stimulating factors of their development, this could lead to the improvement of overall economic and social situation in the region. Two of the most 
important factors that facilitate the international cooperation between organizations are the spread of information communication technologies and the establishment of English language as a universal mean of communication in the business world.

$18.2 \%$ of organizations that took the survey declared that they have business partners in Latvia, the sectors where most of cooperation takes place are trade $(28.6 \%)$, services $(19.0 \%)$ and education $(16.7 \%)$. The type of cooperation corresponds to the branch of economic activity of the partners, most common are purchase of services $(34.1 \%)$, purchase of goods $(18.2 \%)$ and common channels of trade $(18.2 \%)$, as additional areas of cooperation respondents determined the academic cooperation, cooperation in the area of innovations and joint research activities. After analysing the data from the survey it became evident, that although the level of cooperation between organizations of Klaipeda region and Latvia is quite low, there is a big need for such kind of cooperation, $42.8 \%$ of all the organizations that took the survey stated that they would like to cooperate with Latvian organizations and that is more than twice the number of organizations that are currently cooperating, this tendency can be seen in all branches of economic activity.

Only $27.7 \%$ of the respondents stated that the lack of knowledge of foreign language is an obstacle to cooperate with Latvian organizations. Because Latvia and Lithuania are both small countries their people are forced to learn foreign languages. Traditionally the older generation knows Russian and the younger employs English, which is a universal language for doing business internationally, this, is why most of organizations in the region find one or another way to communicate with Latvian organizations. The bigger obstacle for organizations of Klaipeda region to cooperate with Latvian organizations is the lack of information about Latvian business (tax, legal rules, etc.). Even $67.9 \%$ of the organizations that took part in the survey stated that they lack such information and also stated the need of such information in Lithuanian language.

To facilitate the cooperation of organizations from Klaipeda region and Latvia, more information about Latvian business should be provided; if possible it should be in Lithuanian language. There also should be a bigger coordinating role of government institutions from both countries in forming the horizontal cooperation networks, especially between organizations from business, government and science sectors, partners from Latvia could participate in those networks, making them more productive.

KEY WORDS: Klaipeda region, Latvia, cooperation, cross-border.

JEL CODES: R, F230.

Acknowledgment

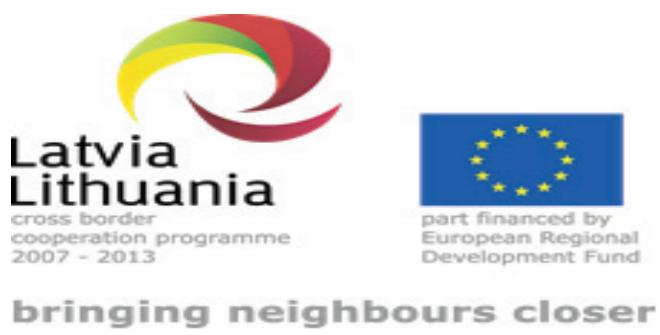

This paper is written using data from project "Formation of methodological framework of regional business growth promotion (LT-LV)" (Project Nr. LV-LT/1.1/LLIII-152/2010). 